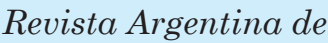

REUMATOLOGÍA

Sociedad Argentina de Reumatología

\title{
Editorial
}

\section{Balance editorial y presentación de una Edición muy relevante}

\author{
Editorial balance and presentation of a very relevant Issue
}

En este 2021 tan particular que concluyó, agradecemos a todos los lectores por haber destinado su tiempo a leer los trabajos que nuestros autores desarrollaron en una época tan difícil, y que lo hayan hecho con tanto esfuerzo, dedicación y profesionalismo. Nuestro habitual agradecimiento a los autores, revisores y al Comité Editorial que hacen posible que la Revista Argentina de Reumatología siga siendo un ícono en la Reumatología Argentina y se haya ganado un espacio en Latinoamérica.

Como todos saben, nuestro próximo objetivo es la indexación en el principal portal del mundo, meta que es ampliamente desafiante y en la cual hace un tiempo iniciamos el camino y esperamos obtener los resultados durante el año venidero.

En 2021 hemos cambiado de Editorial e implementamos varias modificaciones tanto a nivel editorial como en la plataforma de trabajo, la página web, el modo de registrar los trabajos y otros aspectos menos visibles pero importantes para indexar.

En este último número del año, destacamos tres estudios de real importancia para nuestra especialidad.

El primero corresponde a uno de los trabajos más relevantes publicados en 2021 en esta revista y a nivel mundial, del tema actual más preocupante. El estudio se enfoca en los datos del registro SAR-CoVAC en relación a la res- puesta inmune humoral asociada a las vacunas contra SARS-CoV-2 en pacientes con artritis reumatoidea. Evidentemente el estudio de Isnardi y col. no pasará inadvertido por los resultados categóricos presentados.

Por su parte, un tema clave a abordar actualmente con los nuevos tratamientos disponibles es la participación laboral en espondiloartritis. En un estudio de excelente calidad científica, liderado por Schneeberger E y con Airoldi C como primera autora, se presentan los resultados de 129 pacientes con espondiloartritis axial de Argentina que valen la pena analizar.

Otro trabajo interesante es el presentado por el grupo de Abdala $\mathrm{M}$, que refiere a la experiencia propia con la conversión de la prueba cutánea de PPD durante el tratamiento con anti-TNF- $\alpha$, cuyos resultados en parte ya conocíamos por la presentación en el Congreso Argentino, pero que en estas páginas se suman datos novedosos que complementan lo aportado previamente.

Esperamos que disfruten del último número de la Revista Argentina de Reumatología y tengan un excelente comienzo de año.

Dr. Darío Scublinsky Revista Argentina de Reumatología Editor 